\title{
25 Research Soure \\ Host genetics and gut microbiota contribute to feed efficiency in chickens
}

Chaoliang Wen

Wei Yan

Chunning Mai

Zhongyi Duan

Jiangxia Zheng

Congjiao Sun

Ning Yang

\section{Video Byte}

Keywords: Microbiome, chicken, feed efficiency, genetic variations, gut microbiota, spatial heterogeneity, genetic relatedness, host-microbiome interactions, meat production, cecum, duodenum, jejunum, ileum, fecal, feces

Posted Date: October 13th, 2021

DOI: https://doi.org/10.21203/rs.3.rs-967786/v1

License: (c) (i) This work is licensed under a Creative Commons Attribution 4.0 International License.

Read Full License 


\section{Abstract}

Cost of feed is a major expense in chicken production, and that cost has been increasing due to overlap with human food and biofuel production. Therefore, improving feed efficiency can help reduce costs in chicken production systems. Both host genetics and gut microbiota can influence phenotypic traits like feed efficiency. New research explored this relationship in meat-type chickens by examining the host genetics as well as the microbiota from four intestinal regions and feces. Host relatedness showed little correlation to microbial community, but specific host genetic markers were associated with a small number of gut microbes. The greatest effect on feed efficiency, measured by residual feed intake (RFI), was host genetics. Out of the microbiota examined, only the cecum had a significant effect on the observed variance in RFI. Researchers also identified six bacterial groups associated with significant differences in feed efficiency. These results highlight several ways host genetics and microbiomes can influence feed efficiency. They also suggest that encouraging key bacterial taxa combined with selective breeding could improve feed efficiency in chickens. 